\title{
O Plano de Mobilidade Urbana e o futuro das cidades
}

BARBARA RUBIM I e SÉRGIO LEITÃO II

$\mathrm{N}$ O SÉcUlO XIX, o transporte de cargas e o transporte público e privado de pessoas tinham um importante elemento comum: eram todos, em sua maioria, realizados por animais. De fato, o animal era tão utilizado nas cidades que, em Nova York, por exemplo, a frota beirava 200 mil cavalos.

Por volta dos anos 1800, a população de equinos crescia vertiginosamente nas grandes cidades e, com ela, os problemas sociais e sanitários trazidos pela grande quantidade de animais. Para que se tenha uma ideia, por volta de 1890, cada um dos cavalos que compunha a já mencionada frota de Nova York produzia, em média, dez quilos de fezes por dia, totalizando duas mil toneladas de dejetos espalhados pela cidade a cada 24 horas.

Essa situação desesperadora não era exclusiva da cidade norte-americana. O jornal Times de Londres estimou, em 1894, que se não houvesse nenhuma mudança, em meados de 1950 todas as ruas da cidade estariam soterradas sob 2,5 metros de dejetos de cavalo.

Somando-se ao mau cheiro, os excrementos atraíam um enxame enorme de moscas - grandes vetores de doenças - e ratos. Estima-se que, comparativamente, o número de acidentes fatais per capita causados por veículos puxados por cavalos em Nova York em 1900 era 75\% maior que o de acidentes de trânsito atuais (Morris, 2007). Paralelo a isso, o congestionamento provocado pelo uso do cavalo como meio de transporte mais que dobrou entre 1885 e 1905.

Numa das várias tentativas de se minimizar essas questões, Nova York sediou a $1^{\text {a }}$ Conferência Internacional de Planejamento Urbano, em 1898. Na pauta principal do evento estava a busca de uma solução para os problemas causados nas grandes cidades do mundo pelo uso exacerbado do cavalo como meio de transporte.

A Conferência, que tinha duração prevista de sete dias, terminou antes do esperado, sem, no entanto, trazer ao problema qualquer solução definitiva. A situação só viria a ser contornada no começo do século XX, com a disseminação do uso do carro.

A expansão do carro trouxe inúmeros benefícios ao desenvolvimento tecnológico e econômico das cidades, introduzindo mudanças significativas na linha de produção e no mercado de trabalho (fordismo), cujas consequências - positivas e negativas - são sentidas até hoje. Esses fatores fizeram que os investimentos no setor se tornassem constantes, como forma de garantir sua crescente expansão. 
No Brasil, em especial, a preferência ao transporte rodoviário começou a ser dada a partir da Constituição de 1934, com o direcionamento dos esforços para construção de rodovias no país. Em 1956, passamos pela introdução da indústria automobilística, acompanhada, desde então, por políticas públicas de apoio aos veículos automotores, em especial ao carro e à motocicleta.

Essas políticas de incentivo, que persistem até hoje, no entanto, fizeram que, cem anos após a crise vivida pelo uso de cavalos no transporte, o uso do automóvel (outrora uma solução) se tornasse um problema sério nos grandes centros urbanos. Voltamos a enfrentar e discutir os impactos sociais, ambientais e de saúde gerados pelo uso exagerado de um modal no transporte de pessoas: hoje, o carro se tornou o cavalo do século XXI.

\section{A solução do passado, o problema de hoje}

Atualmente, mais de $50 \%$ dos domićlios do Brasil já têm um automóvel ou uma moto em suas garagens. De fato, a frota brasileira de veículos está em franco crescimento, graças à política de incentivos adotada pelo governo desde a década de 1930. Nos últimos dez anos, o número de automóveis no país cresceu $138,6 \%$, enquanto a população brasileira teve expansão de apenas $12,2 \%$ no mesmo período.

Possuir um carro, no entanto, é apenas a ponta do problema da mobilidade nas grandes cidades, agravado pela utilização cotidiana e excessiva do veículo. Prova disso é que, apesar de Nova York ter uma das maiores taxas de motorização do mundo, é em São Paulo que as pessoas gastam mais tempo no deslocamento casa-trabalho.

Em um rol de 31 cidades, a capital paulista perde apenas para Xangai, maior cidade da China. No ranking das dez cidades com maior tempo de deslocamento, cinco são brasileiras e todas aparecem em situação mais crítica que a de Nova York (Ipea, 2013).

O tempo não é a única coisa que as pessoas, e notadamente os brasileiros, perdem nos congestionamentos. Perde-se também saúde, dinheiro e, em alguns casos, até a vida.

O Brasil possui taxas altíssimas de acidentes de trânsito, chegando a ter 22,5 mortes a cada 100 mil pessoas, mais do que a Índia $(18,9)$, a China $(20,5) \mathrm{e}$ o dobro dos Estados Unidos $(11,4)$. Estima-se que o sistema de saúde brasileiro gaste em média R\$ 50 bilhões ao ano com tratamentos e outros custos decorrentes de acidentes de trânsito.

De acordo com estudo feito a cada dois anos pela Fundação Getulio Vargas (FGV), o trânsito de São Paulo acarretou à cidade perdas da ordem de R \$ 40 bilhões em 2012. Isso representa $1 \%$ do PIB do país, com cada cidadão deixando de ganhar ou de gastar cerca de R\$ 3,6 mil enquanto estava preso, de forma totalmente improdutiva, nos congestionamentos.

Quando se analisa a saúde, os números não são menos preocupantes. Em 2011, quase 27 mil internações realizadas na Região Metropolitana de São Paulo 
(RMSP) foram decorrentes da poluição do ar. Na cidade de São Paulo, os gastos com essas internações chegaram a R\$ 31 milhões (Vormitag, 2013).

Há, ainda, a questão do aquecimento global. Se no século XIX o assunto não era presente no cotidiano das pessoas, hoje com certeza cresce em importância ante os efeitos desse fenômeno e a expansão constante das emissões de gases de efeito estufa no país. ${ }^{1}$

Nesse contexto, o setor de transporte é um dos atores principais e ocupa o posto de segundo maior emissor de gases de efeito estufa no país (7\% a 9\% das emissões, ficando atrás somente das queimadas e mudanças no uso do solo - cerca de 70\%). Quando se trata das emissões do setor de energia, no qual o transporte está inserido, ele ainda responde pela maior parte das emissões do setor $(48,23 \%)$.

No tocante às emissões oriundas do transporte de passageiros, $68 \%$ delas são provenientes do transporte individual e $32 \%$, do transporte coletivo (Ministério do Transporte, 2013).

\section{Voltando à estaca zero}

Os números apresentados deixam claro que a solução para o transporte com carros envelheceu e que suas externalidades negativas já são tantas que chegam a superar seus benefícios.

Do ponto de vista de políticas públicas, talvez uma das mais graves consequências trazidas pelo carro tenha sido a apontada por Jared Diamond em seu livro Colapso, no qual sinaliza que o uso do automóvel inviabilizou a projeção de sistemas de transportes públicos que satisfizessem as necessidades da maioria dos moradores das cidades. Citando o caso de Los Angeles, Diamond (2012, p.599) explica que

nossa antiga rede de bondes faliu nos anos de 1920 e 1930, e seus direitos de exploração foram comprados por fabricantes de automóveis e subdivididos de modo que fosse impossível reconstruir a rede (que competia com os automóveis). A preferência dos habitantes de Los Angeles por viver em casas ao invés de prédios e apartamentos, e as longas distâncias e diversas rotas cruzadas pelos trabalhadores tornou impossível projetar sistemas de transporte público que satisfizessem as necessidades da maioria dos residentes.

Isso ocorreu em razão da priorização histórica dada por diversos governos, inclusive o brasileiro, à indústria automobilística, o que levou à marginalização e ao sucateamento de outros modais que não o individual motorizado. Essa priorização cria um ciclo interminável de deterioração das cidades e utilização injusta e antidemocrática do espaço urbano - que precisa ser corrigida com urgência.

Um século após a crise vivida pelas grandes cidades com seu sistema de transporte, voltamos a sonhar e a discutir uma solução de mobilidade que nos redima, desejando que desta vez o remédio de hoje não represente a doença do futuro. 


\section{Um passo rumo à mudança}

Em janeiro de 2012, e após quase 17 anos de tramitação no Congresso Nacional, o Brasil passou a ter uma Política Nacional de Mobilidade Urbana (PNMU). Instituída pela Lei n.12.587/2012, a Política define as diretrizes que devem orientar a regulamentação e o planejamento da mobilidade urbana nas cidades brasileiras.

As diretrizes são claras e podem ser bem resumidas em uma frase: é preciso incentivar os deslocamentos por meios de transporte não motorizados e os coletivos e desestimular os individuais motorizados - responsáveis por $27,4 \%$ dos deslocamentos realizados nas cidades brasileiras com mais de 60 mil habitantes (Associação..., 2012).

Nisso reside o maior mérito da Política: ao obrigar que os gestores das cidades priorizem e incentivem outros modais, ela claramente tenta corrigir a distorção na cultura do planejamento dos deslocamentos que ocorrem no país.

Além de estabelecer diretrizes, a Política traz, ainda, uma determinação clara para os municípios com mais de 20 mil habitantes (30\% das cidades brasileiras): de que elaborem, até abril de 2015, um Plano de Mobilidade Urbana (PMU), capaz de abarcar não só as diretrizes da Lei, mas também de traçar, juntamente à sociedade civil, um planejamento de curto, médio e longo prazos para a forma como se darão os deslocamentos de bens e pessoas na cidade.

Apesar de as determinações da PNMU serem importantes, a ideia de fazer que os municípios brasileiros realizem um planejamento ordenado do setor não é nova. Em 2001, o Estatuto das Cidades (Lei n.10.257/01) - que instituiu a obrigatoriedade do Plano Diretor - determinou que todas as cidades com mais de 500 mil habitantes elaborassem seu Plano de Transportes.

Mudanças no termo (de transporte para mobilidade) à parte, o cerne das duas determinações é o mesmo: o vislumbre, pelo legislador, da necessidade de se regular o setor de transporte de pessoas e cargas.

Não obstante isso, doze anos após o advento do Estatuto das Cidades, a determinação feita por ele ainda continua obscura para boa parte dos gestores. De acordo com o Instituto Brasileiro de Geografia e Estatística (IBGE), somente $55,3 \%$ dos municípios com mais de 500 mil habitantes possuem o Plano de Transporte. Dentre os $44,7 \%$ restantes que também deveriam ter um Plano há mais de uma década, somente $28,9 \%$ o estão elaborando. Se o recorte for ampliado para todos os 5.564 municípios do país, o percentual cai consideravelmente: somente $3,8 \%$ possuem o mencionado instrumento de planejamento (IBGE, 2013).

Esse preocupante cenário demonstra que o retorno da determinação, de forma mais detalhada e aprimorada, veio em boa época, devido a dois fatores principais - um relativo à norma em si e outro externo a ela.

O primeiro é o fato de que além da diferença de denominação já apontada acima, à obrigatoriedade de elaboração do PMU somam-se a ampliação de 
seu universo de abrangência, a determinação de claras diretrizes que deverão orientar sua elaboração e conteúdo e o estabelecimento de que aqueles que descumprirem a norma federal ficarão privados de receber recursos orçamentários federais destinados à mobilidade até que cumpram o disposto na PNMU. ${ }^{2}$

Apesar de a efetividade dessa sanção ser questionável, ela já demonstra um avanço em relação à disposição anterior, cuja ineficácia parcial pode ser atribuída à inexistência, à época, de qualquer sanção para aqueles que a descumprissem.

O segundo fator que faz que a existência de diretrizes federais para a mobilidade seja importante diz respeito ao ciclo de investimentos em mobilidade urbana vivido no país.

Historicamente, a alocação de recursos federais em mobilidade não é constante, grandiosa ou mesmo bem distribuída - entre 2006 e 2010, somente $4 \%$ dos municípios brasileiros receberam verbas federais para o setor, de acordo com levantamento feito pelo Instituto de Pesquisa Econômica Aplicada (Ipea) e divulgado em janeiro/2012.

Dentre os recursos distribuídos, grande parte foi repassada, em geral, para as cidades com mais de um milhão de habitantes (no período citado acima, esse valor correspondeu a $94 \%$ do total), com o repasse de quantias quase sempre irrisórias às cidades que possuem menos de 500 mil habitantes.

Essa realidade, no entanto, tem se alterado pouco a pouco nos últimos anos. Desde meados de 2009, o volume de recursos - sejam do orçamento federal, estadual/ municipal ou via financiamento - que têm sido disponibilizados para a mobilidade cresceu consideravelmente, chegando a mais de R $\$ 90$ bilhões. Mais da metade desses recursos é proveniente do Programa de Aceleração do Crescimento (PAC) da Copa (R\$ 12 bilhões), do PAC Mobilidade Grandes Cidades ( $\mathrm{R} \$ 32,6$ bilhões) e do PAC Mobilidade Médias Cidades (R 8 bilhões).

Aos R 90 bilhões somam-se, ainda, os R $\$ 50$ bilhões anunciados recentemente pela presidenta da República, em junho de 2013.

O Brasil passa, assim, por um dos maiores ciclos de investimento de mobilidade da história, sendo essencial que a alocação desses recursos seja orientada por diretrizes rígidas que priorizem outras formas de deslocamento que não o carro, refletidas, localmente, em um planejamento que trace um inovador perfil de mobilidade para a cidade. Caso contrário, veremos os recursos serem investidos na manutenção de um status quo que privilegia o carro e acaba por sujeitar mais de $60 \%$ da população dos centros urbanos a um sistema de transporte coletivo colapsado.

Superadas essas questões, não se pode negar, no entanto, que a PNMU tem fragilidades estruturais capazes de comprometer a sua efetividade e que merecem atenção.

Uma delas é a falta de previsão sobre qual a forma jurídica que o Plano de Mobilidade Urbana deve ter uma vez elaborado. Na prática, ele pode adotar desde a forma de lei ordinária (na melhor das hipóteses), até mesmo a de 
uma simples apresentação de slides ou de rápida visualização, ${ }^{3}$ que não guarda nenhuma força vinculante capaz de garantir aos cidadãos que o plano será observado pelo poder público. Essa situação é especialmente preocupante se considerarmos o hábito dos governantes brasileiros de abandonar os planos feitos ou iniciados na gestão anterior.

Outra fragilidade é a ausência de explicitação sobre como se dará o processo de avaliação dos Planos que serão apresentados em 2015, processo sobre o qual, inclusive, muito pouco tem se falado até o momento. Essa avaliação é imprescindível para garantir que as disposições da PNMU resultem em um instrumento de planejamento com metas de curto, médio e longo prazos para a mobilidade. Essas metas devem atendar às especificidades de cada cidade, apontadas não só pelos estudos que deverão embasá-lo, mas também pela ampla participação e consulta popular.

Ou seja, sem um rigoroso processo de avaliação, veremos a história se repetir e, tal qual ocorreu com os Planos Diretores, teremos documentos pré-formatados, que podem até ser implantados, mas que não necessariamente trazem em si determinações capazes de transformar a mobilidade e a qualidade de vida dos cidadãos.

Por fim, faltou à Lei em análise uma maior rigidez no momento de estabelecer o papel do governo federal em todo esse processo. Apesar de ser inegável que o regulamento da mobilidade é de competência de cada município, a ausência de uma cultura de planejamento no país levou à crítica situação de escassez de mão de obra. Cabe ao governo federal, nesse ponto, promover essa capacitação e destinar uma fatia do enorme bolo de recursos que hoje estão disponibilizados à mobilidade para a elaboração e capacitação dos profissionais que realizarão a complexa tarefa de reunir, em um documento, os anseios da população para a mobilidade da cidade. Sem essa capacitação, corremos o risco de não conseguirmos entregar nem o PMU, nem os projetos das obras a serem realizadas, essenciais para que o montante hoje disponibilizado para a mobilidade não seja alocado em outro setor pela simples falta de propostas para sua destinação. ${ }^{4}$

Percebe-se, assim, que, apesar de importante, o sucesso da Política Nacional dependerá de outras iniciativas do governo federal e do próprio Ministério das Cidades, que perpassam a necessária regulamentação da Lei n.12.587/12.

Num país em que se tem, nas palavras de Ermínia Maricato, "obra sem plano e plano sem obra", seria ingenuidade acreditar que a elaboração de um plano per se seja capaz de mudar a realidade catastrófica da mobilidade brasileira. De fato, não o é. Mas o cenário composto pela disponibilização de recursos e a existência de diretrizes rígidas voltadas à melhoria da mobilidade gera uma perspectiva promissora que não pode ser desperdiçada: a de que, pela primeira vez, os municípios e gestores têm a obrigação de discutir com a população qual cidade querem ter no futuro. 


\section{É preciso reverter a lógica das cidades}

A construção de uma cidade diferente da que temos hoje, mais inclusiva e socialmente justa, perpassa necessariamente a adoção de duas medidas complementares: a melhoria do transporte público coletivo e a revisão dos benefícios concedidos, de forma direta e indireta, ao usuário do transporte individual motorizado, seja durante a produção, comercialização ou uso do carro.

A relação entre os subsídios e incentivos dados ao transporte individual e ao coletivo é da ordem de oito para um, ou seja, para cada $\mathrm{R} \$ 8,00$ concedidos ao transporte individual, $\mathrm{R} \$ 1,00$ é direcionado ao transporte coletivo (Vasconcellos, 2012b). Essa tendência do governo parece ignorar que, nos grandes centros urbanos, somente $35 \%$ das viagens urbanas motorizadas são realizadas por esse meio, contra 64\% realizadas por ônibus e metrô (Ipea, 2011, p.17).

Apesar disso, estima-se que $80 \%$ do leito carroçável seja ocupado pelos carros. Não é difícil concluir, assim, que os congestionamentos existem porque nossas ruas têm uma capacidade limitada de acomodar veículos e, infelizmente, o sistema atual permite que uma menor parte da população ocupe a maior parte da estrutura viária existente. ${ }^{5}$

No tocante aos subsídios provenientes de incentivos tributários, eles somam, anualmente, montante que varia entre R \$ 8,5 e R\$ 14 bilhões. Esse valor corresponde à renúncia fiscal operada pelo governo federal quando decidiu reduzir o Imposto sobre Produtos Industrializados (IPI) para aquisição de veículos de baixa cilindrada e a Contribuição de Intervenção no Domínio Econômico (Cide-Combustíveis) - reduzida a partir de 2008 até ter sua alíquota zerada em junho de 2012.

No caso da Cide, tributo que incide sobre álcool, petróleo, gás natural e seus derivados e que tinha parte de sua verba destinada a investimentos em infraestrutura de transporte, a renúncia é ainda mais grave. Isso porque representa não só um incentivo ao uso do carro - vez que a redução da alíquota foi usada como manobra para evitar a alta do preço da gasolina, o que oneraria mais os usuários frequentes do transporte individual -, mas também o fim de uma fonte constante de recursos ao setor de transportes.

Além dos incentivos fiscais, os usuários do transporte individual recebem um benefício ainda mais importante ao lhes ser disponibilizado, a um custo extremamente baixo (o do Imposto sobre a propriedade de veículos automotores (IPVA)), o uso de um dos bens mais essenciais da cidade: as ruas.

Se considerarmos que o valor médio do IPVA no Brasil é de R \$ 850,00 (ou R $\$ 2,3$ por dia), cada motorista paga somente $\mathrm{R} \$ 1,15$ para circular e utilizar livremente as ruas da cidade, pois apenas metade da arrecadação é destinada ao município. Percebe-se, facilmente, que esse valor é muito inferior ao gasto por aqueles que dependem do transporte coletivo para realizar seus deslocamentos (Vasconcellos, 2012b).

As vias possuem a função essencial de abrigar grande parte dos desloca- 
mentos, permitindo às pessoas o acesso aos serviços indispensáveis que a cidade guarda.

O espaço que hoje se destina ao estacionamento, gratuito ou não (zona azul), de carros em áreas públicas poderia ser mais bem utilizado se convertido para a instalação de espaços de convivência (mais conhecidos como parklets), ciclovias, ciclofaixas ou mesmo para o alargamento das insuficientes calçadas brasileiras. ${ }^{6}$

Mesmo que pudéssemos imaginar que a cobrança feita para estacionamento em via pública fosse majorada (no caso da zona azul) ou instituída (nas regiões em que nem cobrança há), ainda assim ela não compensaria os prejuízos que a ocupação do espaço público pelo carro gera para a sociedade em geral.

Se, por exemplo, a cidade de São Paulo instituísse cobrança de R\$ 8,00/ dia nas vias onde atualmente não existe cobrança alguma - menos de um quarto dos R\$ 35,00 que, em média, são cobrados pelas redes privadas de estacionamento na capital -, teríamos uma verba anual de mais de R\$ 2 bilhões, ${ }^{7}$ apenas $5 \%$ do valor perdido, em produção e consumo, pela cidade nos congestionamentos (R\$ 40 bilhões), sem se considerar, ainda, todos os outros custos já elencados acima.

Sob esse viés, não faz sentido permitir que os usuários do carro estacionem livremente nas vias da cidade, tornando estático um espaço que poderia ser usado para a melhoria da qualidade de vida da população.

E, caso se pergunte para onde iriam os carros, devemos nos valer do que disse o ex-prefeito de Bogotá, Enrique Peñalosa, quando colocado diante da mesma questão: “o primeiro artigo de todas as constituições democráticas, inclusive a brasileira, diz que todos são iguais perante a lei. Se isso é verdade, um ônibus com 100 passageiros tem direito a 100 vezes mais espaço nas ruas que um carro com uma pessoa". 8

A eliminação dos estacionamentos, sobretudo na área central, é só uma das possíveis mudanças que podem ser realizadas pelos gestores. Outras perpassam a retomada da cobrança da Cide, a instituição da taxa de congestionamento e o estabelecimento de áreas livres da circulação de carros. Essas medidas, em conjunto ou separadamente, são essenciais para se internalizar os custos e as externalidades negativas (abordadas no início deste artigo) geradas pelo uso excessivo do automóvel e retardar sua expansão ilimitada sobre o tecido urbano.

Assim, está claro que é preciso coragem para alterar o atual estado das coisas nas grandes e médias cidades do mundo. Como foi dito no livro infantojuvenil Harry Potter, “chegou a hora de escolhermos entre o que é certo e o que é fácil” (Rowling, 2003). Só isso dará conta da dimensão de ruptura que precisa ser feita com a sociedade industrial e o mundo do automóvel que nos governa desde o começo do século XX.

\section{Uma cidade para todos}

Como em toda mudança profunda de paradigma, a implantação de me- 
didas que restrinjam ou desestimulem, direta ou indiretamente, o uso do carro terá que vencer certa resistência por parte de alguns cidadãos. Sobretudo porque a melhoria geral do transporte coletivo - que facilitará a restrição ao carro - não virá por completo no curto prazo.

Essas medidas, no entanto, são tão necessárias quanto a realização de uma verdadeira revolução no modo como as políticas públicas são pensadas e implementadas no Brasil.

Não faz sentido que a elaboração de políticas para melhorar a mobilidades nas cidades seja pensada apenas no âmbito do Ministério das Cidades, enquanto os Ministérios do Desenvolvimento, Indústria e Comércio, Transportes e Minas e Energia desenvolvem linhas de ação que, na maioria das vezes, contribuem para agravar o problema. Isso vale para as mencionadas políticas de desoneração tributária que, ao reduzirem o preço do carro, como afirma Ricardo Abramovay (2011), esvaziam o pátio das montadoras, mas contribuem para aumentar os índices dos congestionamentos.

Sem que se mude a forma como se dão os planejamentos e planos, feitos de portas fechadas e de forma isolada, sem considerar as outras áreas que influenciam a questão (como é o caso do uso do solo para a mobilidade), continuaremos a gastar tempo e dinheiro com iniciativas que já nascem fadadas ao fracasso ou à irrelevância.

Não existem soluções mágicas para problemas complexos. Mas hoje, diferente do vivido há cem anos com o problema decorrente do uso do cavalo como meio de transporte, não dependemos mais de uma invenção tecnológica para sair dos congestionamentos. As soluções são conhecidas e variadas, algumas mais simples que outras, e envolvem a realização de um planejamento que englobe e considere todos os atores da mobilidade e priorize os transportes não motorizados e coletivos, feito de forma participativa e capaz de transformar efetivamente a forma como as pessoas se deslocam pela cidade.

Se não nos falta tecnologia, certo é que falta aos gestores brasileiros força política para entender que, de fato, devolver à cidade o seu direito de circulação e aos cidadãos o seu direito à cidade, sequestrado que foi pelo uso do automóvel, pode sim trazer conflitos e desgastes políticos. No entanto, o impacto da construção de uma cidade mais justa será, inegavelmente, positivo para todos. É essa percepção que precisa ser construída e trabalhada por todos nós.

\section{Notas}

1 As emissões dos gases de efeito estufa aumentaram 21,5\% entre 2005 e 2010 no setor de energia no Brasil: a fatia passou de $16 \%$ das emissões totais do país para $32 \%$. Foi o setor que mais cresceu no período e o que tende a continuar aumentando, dados os imensos aportes do governo federal direcionados para viabilizar a exploração de petróleo, em especial do pré-sal, que totalizarão aproximadamente R \$ 740 bilhões até 2020. O crescimento das emissões é agravado, ainda, pelo aumento do consumo da gasolina 
em detrimento ao consumo do álcool. Apenas para que se tenha uma ideia, nos anos 2010 e 2011 houve uma queda de $35 \%$, ou quase seis bilhões de litros, nas vendas de etanol. De acordo com $O$ Estado de S. Paulo, “a expansão dos biocombustíveis seria responsável por uma redução de 79 a 89 milhões de toneladas de gás carbônico lançadas na atmosfera até 2020 , numa contribuição de 9 a $8 \%$ da meta total de corte das emissões a que o Governo se comprometeu em 2009. [...] Além disso, documento publicado pelo Ministério do Meio Ambiente, no ano passado, estima que a emissão de gás carbônico por veículos cresceria, até 2020 , a uma média de $4,7 \%$ ao ano, por conta do aumento da frota de veículos no País" ( O Estado de S. Paulo, p.Al2, 5.3.2012, Marta Salomon e Iuri Dantas).

2 Existe alguma controvérsia entre os especialistas com relação a esse ponto. Há quem diga que, não entregue o plano em abril/2015, não há possibilidade de o município vir a elaborá-lo, voltando a se tornar elegível para recebimento das verbas federais. Com respeito, discordamos dessa interpretação, uma vez que o $\$ 4^{\circ}$ do artigo 24 da Lei n.12.587/12 expressamente diz que: “Os Municípios que não tenham elaborado o Plano de Mobilidade Urbana na data de promulgação desta Lei terão o prazo máximo de 3 (três) anos de sua vigência para elaborá-lo. Findo o prazo, ficam impedidos de receber recursos orçamentários federais destinados à mobilidade urbana até que atendam à exigência desta Lei" (grifo nosso).

3 Aqui se destaca o caso da cidade de Belo Horizonte, cujo Plano de Mobilidade (PlanMob BH) somente em setembro/2013 ganhou força de lei (Decreto n.15.317/13), não obstante existir desde 2010. A promulgação do Decreto é positiva, mas inegável que, por ser um ato do Executivo e que não perpassa a Câmara dos Vereadores, não há de ser a melhor forma jurídica a ser adotada para um instrumento que tem como seu pilar a participação popular e o controle social.

4 Nesse sentido, de toda a verba que se pretende investir em mobilidade (R $\$ 140$ bilhões, conforme mostrado anteriormente), somente $10 \%$ dos recursos já foram alocados em empreendimentos. O percentual significativamente baixo se dá exatamente pela falta de projetos apresentados, conforme ressalta matéria do jornal Valor Econômico, publicada no dia 18.10.2013, caderno A6, de autoria de Daniel Rittner e Lucas Marchesini.

5 Essa questão fica ainda mais clara quando se tem em mente que, considerando-se as médias de ocupação diária, o espaço ocupado pelo passageiro do carro $\left(40 \mathrm{~m}^{2}\right)$ é 11 vezes superior ao ocupado pelo passageiro do ônibus $\left(3,6 \mathrm{~m}^{2}\right)$. Se for considerada a lotação máxima do ônibus ( 75 passageiros), a relação vai de 11 para 40 vezes maior. Esse cálculo é feito tendo-se por base que um carro médio possui cinco metros de comprimento e, se trafegar a $40 \mathrm{~km} / \mathrm{h}$, terá uma sombra de 15 metros. Considerando-se que a largura da faixa é de $3 \mathrm{~m}$, o carro ocupa cerca de $60 \mathrm{~m}^{2}$ da via.

6 Sobre esse ponto, a edição de 2012 da pesquisa "DNA Paulistano", realizada pelo Datafolha, surpreendeu ao trazer como resultado que a menção a passeios e asfalto esburacados superou tópicos tradicionais, como segurança, saúde e trânsito. Mais especificamente, a má conservação de ruas e calçadas, que vem ganhando cada vez mais atenção na cena da mobilidade, foi o problema mais citado pelos paulistanos (Editorial Prioridade Pedestre - Folha de S.Paulo, 2.12.2012, p.A2).

7 Cálculo feito tendo por base estimativa de que na Região Metropolitana de São Paulo, $40 \%$ dos motoristas precisam estacionar o carro fora de casa, dos quais $15 \%$ ( 1,2 milhão de veículos) conseguem fazê-lo em via pública, sem pagar (Vasconcellos, 2012a, p.119).

8 Folha de S.Paulo, 24.6.2012, caderno C7. 
Referências

ABRAMOVAY, R. Mobilidade versus carrocentrismo. Folha de S. Paulo, São Paulo, 14 dez. 2011.

ASSOCIAÇÃO NACIONAL DE TRANSPORTE PÚBLICO. Sistemas de Informações da Mobilidade - Relatório Geral 2011. Brasília: ANTP, 2012.

DIAMOND, J. M. Colapso: como as cidades escolbem o fracasso ou o sucesso. Rio de Janeiro: Record, 2012.

INSTITUTO BRASILEIRO DE GEOGRAFIA E ESTATÍSTICA (IBGE). Perfil dos Municípios Brasileiros - 2012. Rio de Janeiro: IBGE, 2013.

INSTITUTO DE PESQUISA ECONÔMICA APLICADA (Ipea). Impactos sociais e econômicos dos acidentes de trânsito nas aglomerações urbanas brasileiras. Brasília: Ipea, 2003.

Emissões relativas de poluentes do transporte motorizado de passageiros nos grandes centros urbanos brasileiros. Brasília: Ipea, 2011.

Tempo de deslocamento casa-trabalho no Brasil (1992 -2009): diferenças entre regiões metropolitanas, níveis de renda e sexo. Brasília: Ipea, 2013.

MARICATO, E. Brasil tem obra sem plano e plano sem obra. São Paulo, Câmara Municipal de São Paulo, 28 mai. 2013. Entrevista a Rodolfo Blancato. Disponível em: <http:// www.camara.sp.gov.br/index.php?option=com_content\&view=article\&id $=15453$ :er minia-maricato-brasil-tem-obras-sem-planos-e-planos-sem-obras\&catid=155:plano-diretor\&Itemid=65>

MINISTÉRIO DO TRANSPORTE. Plano setorial de transporte e de mobilidade urbana para mitigação e adaptação à mudança do clima. Brasília: Ministério do Transporte, 2013.

MORRIS, E. From Horse Power to Horsepower. Access, v.30, 2007.

ROWLING, J. K. Harry Potter e a Ordem de Fênix. Rio de Janeiro: Rocco, 2003.

VASCONCELLOS, E. A. de. Transporte e meio ambiente: conceitos e informações para análise de impactos. São Paulo: Annablume, 2008.

. Mobilidade urbana e cidadania. Rio de Janeiro: Senac Nacional, 2012a.

Transporte urbano no Brasil. Le Monde Diplomatique Brasil, 2012b. Disponí-

vel em: <http://www.diplomatique.org.br/artigo.php?id=1181>.

VORMitAG, E. et al. Pesquisa avaliação do impacto da poluição atmosférica no Estado de São Paulo sob a visão da Saúde. São Paulo: Instituto Saúde e Sustentabilidade, set. 2013.

RESUMO - O artigo traça um breve histórico sobre a evolução dos problemas da mobilidade, dos cavalos aos carros, e mostra que hoje, tal como há cem anos, a priorização do transporte individual levou a problemas sociais, ambientais e de saúde pública. Em seguida, analisa a Política Nacional de Mobilidade Urbana, ressaltando suas inovações e os pontos de atenção que podem prejudicar sua efetividade. Por fim, destaca a neces- 
sidade de se melhorar o transporte coletivo e não motorizado e, concomitantemente, desestimular o uso do automóvel, como formas de se devolver aos cidadãos o direito à cidade e aos serviços essenciais que ela guarda.

PALAVRAS-CHAVE: Automóvel, Cidades, Desincentivo, Mobilidade urbana, Plano de mobilidade urbana.

ABSTRACT - The article starts by providing a brief history of the evolution of mobility problems, from horses to cars, and shows that nowadays, as it was 100 years ago, the prioritization of individual transportation facilities leads to social, environmental and health problems. Secondly, the National Urban Mobility Policy analysis highlights some innovations as well as points of attention that may impair its effectiveness. Lastly, the article advocates the necessity of collective and non-motorized transport and, simultaneously, discourages car use as a way of returning to the citizens the right of the city's space and its services.

KEYWORDs: Automobiles, Cities, Disincentives, Public policies, Urban mobility plan.

Barbara Rubim é advogada e coordenadora da campanha de Clima e Energia do Greenpeace Brasil. @-barbara.rubim@greenpeace.org

Sérgio Leitão é advogado e diretor de Políticas Públicas do Greenpeace Brasil. @ - sergio.leitao@greenpeace.org

Recebido em 15.10.2013 e aceito em 26.10.2013.

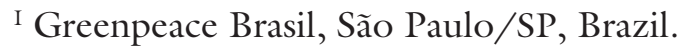

II Greenpeace Brasil, São Paulo/SP, Brazil. 